\title{
Avaliação das características físico-químicas do açúcar mascavo adicionado de açúcar bruto de alta polarização
}

\section{Evaluation of the physicochemical characteristics of brown sugar with added very high polarization raw sugar}

\author{
Lucas de Almeida Andrade' ${ }^{1}$, , Simone Daniela Sartorio de Medeiros ${ }^{2}$, Maria Teresa Mendes Ribeiro Borges ${ }^{2}$ \\ 1 Universidade Federal de São Carlos (UFSCar), Centro de Ciências Agrárias, Departamento de Agroecologia e Desenvolvimento Rural, Araras/SP - Brasil \\ ¿Universidade Federal de São Carlos (UFSCar), Centro de Ciências Agrárias, Departamento de Tecnologia Agroindustrial e Socioeconomia Rural \\ (DTAiSeR-Ar), Araras/SP - Brasil
}

\section{${ }^{*}$ Corresponding Author}

Lucas de Almeida Andrade, Universidade Federal de São Carlos (UFSCar), Centro de Ciências Agrárias, Departamento de Agroecologia e Desenvolvimento Rural, Rodovia Anhanguera, km 174, CEP: 13604-900, Araras/SP - Brasil, e-mail: Idealmeidaandrade@gmail.com

Cite as: Evaluation of the physicochemical characteristics of brown sugar with added very high polarization raw sugar. Braz. J. Food Technol., v. 21, e2017199, 2018.

Received: Nov. 09, 2017; Accepted: May 23, 2018

\section{Resumo}

No Brasil, o açúcar mascavo possui apenas o valor de polarização como padrão de qualidade exigido em legislação própria; entretanto, este valor ( $90 \%$ de polarização) não representa a realidade dos produtos encontrados à venda nos mercados. Além disso, procedimentos como a adição de açúcar bruto de alta polarização (VHP) têm se tornado frequentes, uma vez que esta ação altera a qualidade final do produto e de seu processamento. É essencial, portanto, a elaboração de novos padrões de qualidade a serem exigidos para o açúcar mascavo. Avaliou-se, neste trabalho, a qualidade do açúcar mascavo produzido sem e com adição de VHP, sendo ambos os processos sem e com correção de pH, com o objetivo de fornecer subsídios que possam auxiliar na atualização dos padrões de qualidade do açúcar mascavo no país. Os resultados obtidos demonstram que não houve interação entre a matéria-prima (caldo de cana com diferentes teores de sólidos solúveis iniciais) e o processo utilizado (adição de VHP com e sem correção de pH) que influenciasse as características físico-químicas analisadas, exceto a umidade, em que o processo de adição de açúcar VHP acompanhado de correção de $\mathrm{pH}$ resultou em produtos com menores teores de umidade.

Palavras-chave: Padrão de qualidade; Qualidade de alimentos; Interação produto-processo.

\section{Abstract}

In Brazil, the only quality standard required for brown sugar by specific legislation is the polarization value. However, this value (90\% polarization) does not represent the reality of the products found for sale on the market. In addition, procedures such as the addition of very high polarization (VHP) raw sugar has become commonplace, since this changes the final quality of the product and its processing. The development of new quality standards for brown sugar is essential, thus this work evaluated the quality of brown sugar produced with and without the addition of VHP, both with and without $\mathrm{pH}$ correction, in order to provide subsidies that could aid in updating the quality standards for brown sugar in Brazil. The results obtained demonstrated there was no interaction between the raw material (sugarcane juice with different initial soluble solids contents) and the process used (addition of VHP with and without pH correction) influencing the analyzed physicochemical characteristics, except the humidity, in which the process of addition of VHP sugar accompanied by pH correction resulted in products with lower moisture content.

Keywords: Quality standard; Food quality; Product-process interaction. 


\section{Introdução}

O setor canavieiro, na busca por produtos naturais, redescobriu o açúcar mascavo, que era produzido em larga escala até o início do século XX, quando os pequenos engenhos se transformaram em usinas de açúcar ou fecharam, reduzindo sua produção a quantias insignificantes e restritas a uma atividade industrial familiar (LOPES; BORGES, 1998).

O açúcar mascavo vem sendo cada vez mais valorizado por ser um produto natural e sem aditivos químicos. O seu consumo cresceu nos últimos anos por ser um alimento mais nutritivo em sua composição e vem sendo cada vez mais utilizado para substituir o açúcar refinado (LUCHINI, 2014).

Nos últimos anos, têm sido verificadas mudanças tanto na produção (utilização de equipamentos mais modernos, uso de novas variedades de cana etc.) quanto na comercialização de açúcar em todo o mundo, com reflexos significativos na produção brasileira. O mercado tem se tornado mais exigente em termos de qualidade e segurança do produto, com preferência por tipos especiais de açúcar (SOARES et al., 2008).

Um fator importante da qualidade do açúcar mascavo é o teor de umidade. Em estudo realizado por Verruma-Bernardi et al. (2007), o açúcar mascavo apresentou altos teores de umidade (maior que $8 \%$ ), o que causa problemas na estocagem ao provocar o empedramento do açúcar. Segundo Parazzi et al. (2009), o teor de umidade influencia na conservação e no tempo de armazenamento, sendo que, no açúcar mascavo, esse valor costuma ser mais alto que no açúcar refinado e no cristal. Contudo, os autores afirmaram que novas técnicas de conservação, como, por exemplo, secagem ao ar ou estufa, vêm diminuindo este problema.

O açúcar bruto cuja polarização é maior que 99,2 `S é chamado de VHP, sigla para very high polarization (polarização muito alta) (LOPES; BORGES, 2004b). Para Mandro (2016), o açúcar VHP corresponde a um açúcar que permite aos seus compradores transformá-lo em outros tipos de açúcar, como, por exemplo, o açúcar refinado.

O objetivo deste trabalho foi adicionar açúcar VHP no processo de fabricação do açúcar mascavo e avaliar o quanto esta adição é capaz de modificar as características físico-químicas do produto, por meio da determinação dos teores de umidade, Brix, polarização, pH, açúcares redutores $(A R)$, açúcares redutores totais (ART), cinzas calcinadas e cinzas condutimétricas.

\section{Material e métodos}

\subsection{Produção do açúcar mascavo}

O estudo foi realizado no Laboratório de Análise e Simulação Tecnológica (LAST), do Departamento de Tecnologia Agroindustrial e Socioeconomia Rural
(DTAiSER - Ar), pertencente ao Centro de Ciências Agrárias (CCA), da Universidade Federal de São Carlos (UFSCar), campus Araras-SP.

Para produzir o açúcar mascavo, foram utilizados como matéria-prima caldos de cana conduzida em manejo orgânico, com diferentes teores de sólidos solúveis iniciais. Os caldos foram congelados a $-18^{\circ} \mathrm{C}$ até o momento da produção do açúcar. O experimento foi repetido uma única vez. Os caldos foram descongelados e separados em:

- Caldo 1-13 L e teor de sólidos solúveis inicial de 17,1 ${ }^{\circ}$ Brix;

- Caldo 2- 13 L e teor de sólidos solúveis inicial de 19,9 ${ }^{\circ}$ Brix;

- Caldo 3- 13 L e teor de sólidos solúveis inicial de $21,3^{\circ}$ Brix.

Para as medições de sólidos solúveis, foi utilizado um refratômetro automático modelo Reichert R2i300. Cada caldo foi dividido em três partes: uma parte não recebeu nenhum processo de produção, uma segunda parte recebeu adição de açúcar VHP e a terceira parte recebeu adição de açúcar VHP acompanhada de correção de pH.

Os caldos foram colocados em tachos abertos para evaporação da água e a elevação do ponto de ebulição foi controlada com termômetro digital, até que se atingisse a temperatura de $120^{\circ} \mathrm{C}$. Quando atingida esta temperatura, cada tacho foi retirado do fogo e começou o processo de cristalização da massa através da agitação manual, até que o açúcar mascavo ficasse seco e solto. Após o resfriamento, as amostras foram acondicionadas em potes plásticos devidamente identificados e armazenados em sala com umidade relativa do ar inferior a $60 \%$ e $20^{\circ} \mathrm{C}$, até a realização das análises físico-químicas.

\subsection{Análises físico-químicas}

Para todos os tratamentos, foram analisados em triplicata os seguintes parâmetros: polarização (Pol), sólidos solúveis totais (Brix), umidade, pH, acidez, cinzas condutimétricas, cinzas calcinadas, açúcares redutores (AR) e açúcares redutores totais (ART).

\subsubsection{Determinação de polarização (Pol) e sólidos solúveis totais}

Para a determinação de Pol e sólidos solúveis totais, foi utilizada a metodologia ICUMSA GS1 1/2/3/9-1 (ICUMSA, 2011) modificada para açúcar mascavo. Foram pesados 13,00 g de açúcar mascavo e transferidos para balão volumétrico de $200 \mathrm{~mL}$, completando-se o volume com água destilada. Uma pequena parte desse volume foi separada para leitura de Brix em refratômetro automático modelo Reichert R2i300. O restante (cerca de $180 \mathrm{~mL}$ ) 
Avaliação das características físico-químicas do açúcar mascavo adicionado de açúcar bruto de alta polarização

Andrade, L. A. et al.

foi separado para a clarificação necessária para leitura sacarimétrica.

A clarificação foi feita com uma mistura homogênea de $\mathrm{CaOH}: \mathrm{AlCl}_{3}$ : Celite na proporção 1: 2: 4. Foram adicionados $12 \mathrm{~g}$ da mistura clarificante em cada Becker contendo a solução de açúcar mascavo. O conteúdo foi agitado e filtrado em papel filtro. O filtrado foi utilizado para a determinação de Pol em um sacarimêtro modelo Rudolph Research Analytical Autopol 1.

\subsubsection{Determinação de umidade}

O teor de umidade foi determinado por método gravimétrico, ou seja, secagem em estufa a $105^{\circ} \mathrm{C}$ por 24 horas, em dois períodos pós-fabricação do açúcar. A umidade foi medida após três e seis meses de fabricação do mascavo, para o acompanhamento da dinâmica de absorção de umidade do produto.

\subsubsection{Determinação de $\mathrm{pH}$}

A determinação de $\mathrm{pH}$ foi realizada diretamente, com a imersão do eletrodo em uma solução 5\% do açúcar mascavo.

\subsubsection{Cinzas condutimétricas e cinzas calcinadas}

A determinação de cinzas condutimétricas foi realizada pelo método ICUMSA GSI 1/3/4/7/8-13 (ICUMSA, 1994). Para a determinação de cinzas calcinadas, utilizou-se a técnica gravimétrica de calcinação a $600{ }^{\circ} \mathrm{C}$ por 4 horas.

\subsubsection{Determinação de acidez}

Para a determinação do valor de acidez, foi utilizada uma titulação ácido-base, conforme metodologia descrita por Zenebon et al. (2008).

\subsubsection{Determinação do teor de açúcares redutores (AR) e açúcares redutores totais (ART)}

As determinações de AR e ART foram feitas pelo método de Somogyi e Nelson, segundo Amorim et al. (1979), adaptado para açúcar mascavo.

\section{Análise estatística}

A análise de variância univariada (ANOVA) foi realizada para cada variável resposta, considerando um Delineamento Inteiramente Casualizado (DIC) em esquema fatorial 3 (matéria-prima) × 3 (processo), com 3 repetições. Quando necessário, foi utilizado o Teste de Tukey no nível de significância de 5\%. Para a variável ART, foi utilizado o teste não paramétrico Scheirer-Ray-Hare (DYTHAM, 2011), pois não foram satisfeitas as pressuposições da ANOVA.

\section{Resultados e discussão}

De acordo com p-valor menor que 0,05, a interação foi significativa apenas para as variáveis umidade e umidade seis meses após a fabricação, indicando que o tipo de matéria-prima dependeu do tipo de processo (Tabela 1).

O resumo das análises para as variáveis Pol (\%), Brix, cinzas condutimétricas (\%), cinzas calcinadas (\%), pH, acidez, AR (\%) e ART (\%) encontra-se nas Tabelas 2 e 3.

Os resultados de polarização (\%Pol), que representam o teor de sacarose aparente em g/100 g de açúcar, foram valores inferiores ao exigido pela legislação brasileira, que afirma que o açúcar mascavo deve apresentar um valor mínimo de 90\% de Pol (BRASIL, 1978). O processo de adição de VHP (Tabela 2) apresentou uma melhora significativa do valor médio do teor de sacarose aparente e, quando acompanhado de correção de $\mathrm{pH}$ o valor médio obtido ficou ainda mais próximo ao indicado pela legislação. Esta mesma legislação infere que o valor de Pol é o único parâmetro a ser considerado para o açúcar mascavo.

Contudo, este valor legal já vem sendo questionado por outros pesquisadores, pelo fato de não corresponder às características encontradas nos produtos comerciais. Por exemplo, Araújo et al. (2011) relataram que, das 10 amostras de açúcar mascavo produzidas por uma agroindústria familiar, apenas três apresentaram valores de acordo com a legislação. Em outro trabalho, Generoso et al. (2009) concluíram que, das 31 amostras de açúcar comercial analisadas, apenas sete apresentaram o valor regulamentado. Verruma-Bernardi et al. (2007)

Tabela 1. Valor-p dos testes da ANOVA, em que as causas de variação (C.V.) foram matéria-prima (MP), processo (P) e a interação entre estes $(\mathrm{MP} \times \mathrm{P})$

\begin{tabular}{|c|c|c|c|c|c|c|c|c|c|c|}
\hline \multirow[b]{2}{*}{ C.V. } & \multicolumn{10}{|c|}{ Variável resposta } \\
\hline & Pol (\%) & ${ }^{\circ}$ Brix & $\begin{array}{c}\text { Cinzas } \\
\text { Condut. } \\
(\%)\end{array}$ & $\begin{array}{c}\text { Cinzas } \\
\text { Calcinadas } \\
(\%)\end{array}$ & pH & $\begin{array}{c}\text { Acidez } \\
(\%)\end{array}$ & AR (\%) & $\begin{array}{l}\text { ART } \\
(\%)\end{array}$ & $\begin{array}{c}\text { Umidade } \\
(\%)\end{array}$ & $\begin{array}{c}\text { Umidade_6m* } \\
(\%)\end{array}$ \\
\hline MP & 0,00 & 0,07 & 0,00 & 0,00 & 0,00 & 0,00 & 0,00 & 0,05 & 0,00 & 0,00 \\
\hline$P$ & 0,00 & 0,86 & 0,00 & 0,00 & 0,04 & 0,68 & 0,00 & 0,32 & $<0,05$ & 0,00 \\
\hline$M P \times P$ & 0,24 & 0,71 & 0,07 & 0,09 & 0,09 & 0,50 & 0,76 & 0,10 & $<0,05$ & 0,03 \\
\hline
\end{tabular}

*Umidade $6 \mathrm{~m}=$ Umidade seis meses após a fabricação. Pol= polarização, Condut. =condutimétricas, $\mathrm{AR}=$ açucares redutores, $\mathrm{ART}=$ açucares redutores totais. 
Avaliação das características físico-químicas do açúcar mascavo adicionado de açúcar bruto de alta polarização Andrade, L. A. et al.

Tabela 2. Propriedades físico-químicas de açúcar mascavo produzido por diferentes processos.

\begin{tabular}{|c|c|c|c|c|c|c|c|c|}
\hline Processo & $\begin{array}{l}\text { Pol } \\
(\%)\end{array}$ & ${ }^{\circ}$ Brix & $\begin{array}{c}\text { Cinzas } \\
\text { Condut. } \\
(\%)\end{array}$ & $\begin{array}{c}\text { Cinzas } \\
\text { Calcinadas } \\
(\%)\end{array}$ & $\mathbf{p H}$ & Acidez (\%) & $\begin{array}{l}\text { AR } \\
(\%)\end{array}$ & $\begin{array}{c}\text { ART } \\
(\%)\end{array}$ \\
\hline \multirow{2}{*}{ Testemunha } & $71,1 \mathrm{c}$ & $93,4 a$ & $1,64 a$ & $1,20 a$ & $5,15 b$ & $1,32 \mathrm{a}$ & $12,96 a$ & $0,73 a$ \\
\hline & $(4,92)$ & (2.72) & $(0,09)$ & $(0,13)$ & $(0,20)$ & $(0,33)$ & $(2,34)$ & $(0,07)$ \\
\hline \multirow{2}{*}{ VHP } & $75,1 b$ & $93,4 a$ & $1,11 \mathrm{c}$ & $0,85 b$ & $5,15 b$ & $0,88 b$ & $12,53 a$ & $0,78 a$ \\
\hline & $(3,94)$ & $(2,42)$ & $(0,09)$ & $(0,09)$ & $(0,19)$ & $(0,09)$ & $(2,99)$ & $(0,06)$ \\
\hline \multirow{2}{*}{$\mathrm{VHP}+\mathrm{pH}$} & $84,5 a$ & $96,2 a$ & $1,19 b$ & $0,91 b$ & $6,0 \mathrm{a}$ & $0,81 b$ & $6,07 b$ & $(0,78) a$ \\
\hline & $(1,8)$ & $(2,13)$ & $(0,08)$ & $(0,08)$ & $(0,18)$ & $(0,08)$ & $(1,66)$ & $(0,05)$ \\
\hline
\end{tabular}

$\mathrm{Pol}=$ polarização; Condut. =condutimétricas, $\mathrm{AR}=$ açucares redutores, $\mathrm{ART}=$ açucares redutores totais, $\mathrm{VHP}=$ adição de açúcar bruto de alta polarização, VHP+pH= adição de açúcar bruto de alta polarização com correcãa de pH. Médias seguidas da mesma letra na coluna não diferem, estatisticamente, no nível de 5\% de probabilidade pelo Teste de Tukey; os números entre parênteses referem-se ao desvio padrão.

Tabela 3. Valores médios das variáveis respostas de Pol, Brix, cinzas calcinadas, cinzas condutimétricas, acidez, AR e ART submetidas a diferentes matérias-primas (MP).

\begin{tabular}{|c|c|c|c|c|c|c|c|c|}
\hline $\begin{array}{c}\text { Matéria- } \\
\text { prima }\end{array}$ & $\begin{array}{l}\text { Pol } \\
(\%)\end{array}$ & ${ }^{\circ}$ Brix & $\begin{array}{c}\text { Cinzas } \\
\text { Condut. } \\
(\%)\end{array}$ & $\begin{array}{c}\text { Cinzas } \\
\text { Calcinadas } \\
(\%)\end{array}$ & pH & $\begin{array}{c}\text { Acidez } \\
(\%)\end{array}$ & $\begin{array}{l}\text { AR } \\
(\%)\end{array}$ & $\begin{array}{l}\text { ART } \\
(\%)\end{array}$ \\
\hline \multirow{2}{*}{$\mathrm{C} 1$} & $79,67 a$ & $94,01 a$ & $1,22 \mathrm{c}$ & $0,92 b$ & $5,3 a$ & $1,06 a$ & $9,19 b$ & $0,8 a$ \\
\hline & $(5,39)$ & $(3,58)$ & $(0,26)$ & $(0,14)$ & $(0,50)$ & $(0,42)$ & $(3,21)$ & $(0,07)$ \\
\hline \multirow{2}{*}{$\mathrm{C} 2$} & $78,03 a$ & $94,73 a$ & $1,42 a$ & $1,11 \mathrm{a}$ & $5,52 a$ & $0,99 a$ & $9,19 b$ & $0,77 a$ \\
\hline & $(5,70)$ & $(1,71)$ & $(0,25)$ & $(0,21)$ & $(0,49)$ & $(0,20)$ & $(3,25)$ & $(0,05)$ \\
\hline $\mathrm{C} 3$ & $\begin{array}{c}73,03 \mathrm{~b} \\
(7,80)\end{array}$ & $\begin{array}{c}94,07 a \\
(2,85)\end{array}$ & $\begin{array}{l}1,30 b \\
(0,23)\end{array}$ & $\begin{array}{l}0,93 b \\
(0,15)\end{array}$ & $\begin{array}{l}5,53 a \\
(0,47)\end{array}$ & $\begin{array}{l}0,96 a \\
(0,27)\end{array}$ & $\begin{array}{c}13,18 a \\
(4,23)\end{array}$ & $\begin{array}{l}0,73 a \\
(0,05)\end{array}$ \\
\hline
\end{tabular}

C1= caldo $1 \mathrm{com}$ teor de sólidos solúveis inicial de 17,1 ${ }^{\circ}$ Brix, C2= caldo 2 com teor de sólidos solúveis inicial de $19,9^{\circ}$ Brix, $\mathrm{C} 3=\mathrm{caldo} 3 \mathrm{com}$ teor de sólidos solúveis inicial de $21,3^{\circ}$ Brix. Pol= polarização, Condut.=condutimétricas $A R=$ açucares redutores, $A R T=$ açucares redutores totais, VHP= adição de açúcar bruto de alta polarização. Médias seguidas da mesma letra na coluna não diferem, estatisticamente, no nível de $5 \%$ de probabilidade pelo Teste de Tukey; os números entre parênteses referem-se ao desvio padrão.

analisaram nove amostras de açúcar mascavo e apenas duas apresentaram valores acima de 90\% de Pol.

Faria (2012), ao comparar uma marca de açúcar mascavo orgânico comercial com outros tipos de açúcares (cristal orgânico, cristal convencional, demerara orgânico e refinado orgânico), encontrou valores de Pol acima de 90\%, exceto para o açúcar mascavo orgânico, que apresentou um valor de $85,9 \%$ de Pol. Como o valor de Pol é o único parâmetro estipulado pela legislação, recomenda-se um estudo para a revisão desse valor, com a finalidade de atualizar os padrões de qualidade do açúcar mascavo no país.

Os valores de Brix foram semelhantes em todos os aspectos, como demonstra a Tabela 2, lembrando-se de que tanto a legislação como a literatura não apresentam dados de valores de Brix para açúcar mascavo. Essa determinação é extremamente simples e pode ser utilizada por produtores familiares. Assim, torna-se interessante pesquisar o uso desta medida na determinação rápida de umidade, pois Brix $=100-\%$ umidade.
Os valores de cinzas condutimétricas e de cinzas calcinadas diminuíram com o processo de adição de VHP sem e com correção de pH, quando comparados com os valores da testemunha, como demonstra a Tabela 2. Lopes e Borges (2004c) propõem um valor de até 2,2\% de cinzas para açúcar mascavo. Valores muito elevados representam alto teor de potássio, o que pode conferir um sabor desagradável ao açúcar, além de dificultar a sua cristalização. Para Verruma-Bernardi et al. (2007), os valores de cinzas para açúcar mascavo variaram de $1,21 \%$ a 5,58\%, diversamente de Araújo et al. (2011) que encontraram valores de $0,7 \%$ a 1,4\% de cinzas calcinadas em açúcar mascavo. Das amostras comerciais de açúcar mascavo analisadas por Generoso et al. (2009), os valores de cinzas variaram de $1,15 \%$ a 3,45\%. Faria (2012), ao analisar uma amostra de mascavo orgânico, encontrou o valor de 1,35\% de cinzas. Pode-se concluir que os valores de cinzas encontrados neste trabalho estão de acordo com a literatura, não havendo grande discrepância entre os trabalhos. Mas é perceptível que, em todos os trabalhos, incluindo este, muitas amostras de açúcar estão de acordo 
com o valor de 2,2\% de cinzas proposto por Lopes e Borges (2004c). Além disso, é perceptível que há muita variação nos valores das diferentes amostras analisadas por este e outros autores, o que pode ser explicado pela diferença varietal, pelas condições edafoclimáticas e pela condução da cultura da cana-de-açúcar utilizada. Não foram encontrados na literatura artigos que justifiquem o valor proposto por Lopes e Borges (2004c); assim, este artigo propõe que análises físico-químicas e análises sensoriais sejam feitas para melhor comprovar o valor de 2,2\% como sendo o limite máximo que não cause o sabor desagradável.

Em relação ao valor de pH, Generoso et al. (2009) obtiveram valores que variam de 5,22 a 7,85. Faria (2012) encontrou na amostra de açúcar mascavo orgânico o valor de pH igual a 6,0. Esta variação, segundo Lopes e Borges (2004a), pode ser explicada pela adição de cal no caldo, processo comum na indústria de açúcar mascavo, ressaltando que os mesmos afirmam que não há um valor mínimo ou máximo especificado para tal procedimento. Andrade (1998) relatou que, para se evitar a inversão da sacarose que ocorre em meio ácido, as condições de trabalho durante o processamento do caldo devem ser monitoradas, de forma que o $\mathrm{pH}$ permaneça, a maior parte do tempo, próximo da neutralidade. As análises deste trabalho demonstram que o valor de $\mathrm{pH}$ está de acordo com os outros autores. $\mathrm{O} \mathrm{pH}$ é facilmente monitorado com papel universal. A proposta é o monitoramento deste parâmetro em açúcar mascavo, apenas como forma de prever o tipo de processamento ao qual foi submetido o açúcar. Todos os tipos de açúcares com pH superior a 6,00 provavelmente sofrerão a neutralização do caldo, impedindo, assim, a inversão de sacarose, o que pode acarretar retenção de umidade no mascavo.

Na literatura, não foram encontrados valores de acidez para açúcar mascavo. Pesquisas sobre acidez podem ser realizadas visando compreender o comportamento dos ácidos orgânicos frente à neutralização dos caldos. Algumas variedades são ricas em determinados ácidos orgânicos, como o aconítico, que levam a um tamponamento do caldo e, consequentemente, a uma dificuldade na neutralização. Esta é de grande importância para evitar hidrólise da sacarose e facilitar a cristalização. A determinação dos valores de acidez neste trabalho teve o objetivo de monitorar a formação dos ácidos orgânicos pela destruição dos açúcares redutores durante o tempo de aquecimento do caldo. Tanto a adição de VHP como a adição de VHP com correção de pH são procedimentos favoráveis à não formação de ácidos orgânicos. Os valores de acidez na Tabela 2 são semelhantes para adição de VHP e adição de VHP mais correção pH.

Os valores obtidos por Generoso et al. (2009) mostraram uma variação de $A R$ entre 1,17\% e 8,51\%. Verruma-Bernardi et al. (2007) verificaram uma variação entre 1,43\% e 7,25\%. Faria (2012) encontrou, na amostra de açúcar mascavo orgânico, o valor de 5,6\% de AR. Araújo et al. (2011) encontraram valores de AR para açúcar mascavo que variaram entre 2,8\% e 7,4\% De acordo com Lopes e Borges (2004c), os valores de AR devem estar abaixo de 2,4\%. Valores muito elevados de AR dificultam a cristalização da sacarose, além de resultar um açúcar úmido e muito empedrado. A umidade diminui a vida de prateleira por causa da contaminação por fungos e bolores. Os autores afirmaram que os açúcares redutores podem ser originários da própria cana (variedade e maturação) ou da inversão da sacarose, no processo de fabricação.

Este limite máximo de AR apresentado por Lopes e Borges (2004c) - que não foi verificado neste experimento pode ser questionado em função da grande variação encontrada na literatura. Por ser tecnicamente difícil obter valores tão baixos de AR, é necessária a padronização com teores mais factíveis e que garantam a qualidade do produto. Observou-se que tanto o processo sem adição de VHP e sem correção de pH como o processo somente com adição de VHP produziram açúcares com altos teores de AR. Este alto teor de AR é responsável pela umidade do açúcar, já que os açúcares redutores são higroscópicos. O processo com adição de VHP e correção de $\mathrm{pH}$ apresentou um valor que difere dos outros dois processos. Propõe-se que estudos de teor de AR sejam feitos, para adequar os padrões a serem exigidos pela legislação.

Em relação a ART, que é a soma de sacarose e açúcares redutores presentes no produto, verificou-se que não houve interação entre matéria-prima e processo. Nem mesmo a correção de $\mathrm{pH}$ ajudou a elevar os valores de ART, pois a correção eleva o pH, ou seja, diminui a acidez, impedindo a inversão e destruição de açúcares. Generoso et al. (2009) encontraram valores de ART que variaram entre $68,90 \%$ e $98,21 \%$ e ressaltaram que não existem valores de máximos e mínimos para este parâmetro analisado.

Nas Tabelas 4 e 5 encontram-se os teores de umidade inicial e após seis meses de fabricação. É perceptível a influência da adição de açúcar VHP e da correção de $\mathrm{pH}$ nos valores de umidade. Claramente, o açúcar VHP contribuiu para a diminuição dos teores de umidade e, quando acompanhado da correção de pH, sua ação foi potencializada, diminuindo ainda mais a umidade. Isso ocorre porque a presença de uma alta concentração de açúcar inicial diminuiu o tempo de evaporação, evitando a inversão da sacarose.

Para Verruma-Bernardi et al. (2007), altos teores de umidade em açúcar mascavo podem causar problemas, como empedramento, dissolução de cristais, contaminação por micro-organismos e inversão da sacarose, diminuindo a vida de prateleira do produto. Esses autores encontraram valores de umidade que variavam de 1,35\% a 4,44\% e 
Avaliação das características físico-químicas do açúcar mascavo adicionado de açúcar bruto de alta polarização Andrade, L. A. et al.

Tabela 4. Valores médios das interações significativas da análise de variância referente à umidade (\%) do açúcar mascavo, submetido a diferentes processos e matéria-prima.

\begin{tabular}{cccc} 
Matéria-prima & \multicolumn{3}{c|}{ Processo } \\
\cline { 2 - 4 } C1 & Testemunha & VHP & VHP+pH \\
& $7,18 \mathrm{aB}$ & $6,66 \mathrm{aB}$ & $4,03 \mathrm{bB}$ \\
C2 & $(0,37)$ & $(0,16)$ & $(0,28)$ \\
& $7,14 \mathrm{aB}$ & $7,60 \mathrm{aA}$ & $5,00 \mathrm{bA}$ \\
C3 & $(0,13)$ & $(0,28)$ & $(0,38)$ \\
& $9,23 \mathrm{aA}$ & $8,04 \mathrm{bA})$ & $4,02 \mathrm{cB}$ \\
\hline
\end{tabular}

C1= caldo $1 \mathrm{com}$ teor de sólidos solúveis inicial de $17,1^{\circ}$ Brix, C2= caldo $2 \mathrm{com}$ teor de sólidos solúveis inicial de $19,9^{\circ}$ Brix, C3= caldo $3 \mathrm{com}$ teor de sólidos solúveis inicial de $21,3^{\circ}$ Brix, VHP= adição de açúcar bruto de alta polarização, VHP+pH= adição de açúcar bruto de alta polarização com correção de pH Médias seguidas da mesma letra na linha não diferem, estatisticamente, no nível de $5 \%$ de probabilidade pelo Teste de Tukey na relação processo da matéria-prima; médias seguidas da mesma letra na coluna não diferem, estatisticamente, no nível de $5 \%$ de probabilidade pelo Teste de Tukey na relação matéria-prima do processo; os números entre parênteses referem-se ao desvio padrão.

Tabela 5. Valores médios das interações significativas da análise de variância referente à umidade seis meses após a fabricação (\%) do açúcar mascavo, submetido a diferentes processos e matéria-prima.

\begin{tabular}{cccc} 
Matéria-Prima & \multicolumn{3}{c}{ Processo } \\
\cline { 2 - 4 } & Testemunha & VHP & VHP+pH \\
C1 & $9,55 \mathrm{aB}$ & $8,15 \mathrm{bB}$ & $4,53 \mathrm{cB}$ \\
& $(0,28)$ & $(0,61)$ & $(0,3)$ \\
C2 & $9,17 \mathrm{aB}$ & $8,66 \mathrm{aB}$ & $5,22 \mathrm{bAB}$ \\
& $(0,31)$ & $(0,04)$ & $(0,04)$ \\
C3 & $10,83 \mathrm{aA}$ & $9,47 \mathrm{bA}$ & $5,51 \mathrm{cA}$ \\
& $(0,66)$ & $(0,18)$ & $(0,34)$ \\
\hline
\end{tabular}

C1= caldo 1 com teor de sólidos solúveis inicial de 17,1 ${ }^{\circ}$ Brix, C2= caldo 2 com teor de sólidos solúveis inicial de $19,9^{\circ}$ Brix C3= caldo 3 com teor de sólidos solúveis inicial de $21,3^{\circ}$ Brix, VHP= adição de açúcar bruto de alta polarização, VHP+pH= adição de açúcar bruto de alta polarização com correção de pH Médias seguidas da mesma letra na linha não diferem, estatisticamente, no nível de $5 \%$ de probabilidade pelo Teste de Tukey na relação processo da matéria-prima; médias seguidas da mesma letra na coluna não diferem, estatisticamente, no nível de $5 \%$ de probabilidade pelo Teste de Tukey na relação matéria-prima do processo; os números entre parênteses referem-se ao desvio padrão.

recomendam um padrão inferior a 2,4\% de umidade para açúcar mascavo.

Segundo Araújo et al. (2011), os valores de umidade encontrados para açúcar mascavo variaram de 1,1\% a $3,7 \%$. Jesus (2010) encontrou, em marcas comerciais de açúcar mascavo, valores médios de 1,95\% a 3,67\%. Entre as marcas analisadas por Generoso et al. (2009), o maior valor encontrado foi de $4,89 \%$ de umidade. Em outro estudo, Faria (2012) encontrou o valor de 2,90\% de umidade para açúcar mascavo orgânico.

Os valores encontrados na literatura contrastam com os valores médios de umidade obtidos neste experimento, que são mais altos que as marcas comerciais e que não possuem adição de VHP. Os valores do experimento podem ser explicados, pois a primeira aferição de umidade foi feita três meses após a produção do açúcar mascavo e, durante o tempo de armazenagem, ocorreu acréscimo de umidade, devido ao tipo de embalagem utilizada e da manipulação para realizar as análises. Outro motivo é que as marcas comerciais submetem o açúcar mascavo a algum processo de secagem, para aumentar a vida de prateleira, o que nos leva a recomendar esta etapa de processamento. Este procedimento causa também um aumento no valor de polarização dos produtos e, neste trabalho, os valores de polarização foram inferiores aos analisados por outros autores.

Isto posto, três meses após a medição de umidade, foi feita uma nova medida, para verificar se durante o processo de armazenamento o açúcar mascavo poderia ganhar umidade. Os teores de umidade após seis meses da produção variaram de 5,22\% a 15,29\%. Todas as amostras apresentaram aumento no teor de umidade, ou seja, se as condições de armazenamento não forem adequadas, a presença de açúcares redutores, que são higroscópicos, alterará a umidade do produto.

\section{Conclusões}

O processo de adição de açúcar bruto de alta polarização na fabricação do açúcar mascavo não foi capaz de promover alterações significativas nas características físico-químicas estudadas, com exceção do teor de umidade. A adição de VHP foi responsável por diminuir este valor, o que favorece a estabilidade do produto final, pois quanto menor o teor médio de umidade no açúcar mascavo, maior será sua vida de prateleira. 
Avaliação das características físico-químicas do açúcar mascavo adicionado de açúcar bruto de alta polarização Andrade, L. A. et al.

Recomenda-se que a legislação brasileira seja revisada, já que indica apenas o valor de polarização como padrão de qualidade para açúcar mascavo, sendo acrescentados novos parâmetros a serem observados pelos produtores, principalmente em relação aos teores de açúcar redutor, açucares redutores totais e umidade.

\section{Referências}

AMORIM, H. V.; MORAES, M. J.; ZAGO, E. A. Determinação de ART e AR em mostro, caldo e melaço pelo método colorimétrico de Somogyi e Nelson. In: CONGRESSO BRASILEIRO DA STAB, 1., 1979, Maceió. Anais... Piracicaba: STAB, 1979. p. 94-97.

ANDRADE, A. R. P. Tratamento do caldo: manual técnico da usina de açúcar Santa Terezinha. Santana do Paraíba: [s.n.], 1998.

ARAÚJO, E. R.; BORGES, M. T. M. R.; CECCATO-ANTONINI, S. R.; VERRUMA-BERNARDI, M. R. Qualidade de açúcares mascavo produzidos em um assentamento da reforma agrária. Alimentos e Nutrição, v. 22, n. 4, p. 617-621, 2011.

BRASIL. Resolução CNNPA n 12/33, de 1978. Diário Oficial [da] República Federativa do Brasil, Brasília, DF, 1978, 24 jul. 1978.

DYTHAM, C. Choosing and using statistics. A Biologist's guide. 3rd ed. USA: Wiley-Brackwell, 2011.

FARIA, D. A. M. Estudo nutricional e sensorial de açúcares cristal, refinado, demerara e mascavo orgânicos e convencionais. 2012. 74 f. Dissertação (Mestrado em Agroecologia e Desenvolvimento Rural)--Universidade Federal de São Carlos, Araras, 2012.

GENEROSO, W. C.; BORGES, M. T. M. R.; CECCATO-ANTONINI, S. R.; MARINO, A. F.; SILVA, M. V. M.; NASSU, R. T.; VERRUMABERNADI, M. R. Avaliação microbiológica e físico-química de açúcares mascavo comerciais. Revista do Instituto Adolfo Lutz, v. 2, n. 68, p. 259-268, 2009.

INTERNATIONAL COMMISSIOM FOR UNIFORM METHODS OF SUGAR ANALYSIS - ICUMSA. Methods books. USA: ICUMSA, 1994.

INTERNATIONAL COMMISSIOM FOR UNIFORM METHODS OF SUGAR ANALYSIS - ICUMSA. Methods books. USA: ICUMSA, 2011.

JESUS, D. A. Qualidade microbiológica de amostras de açúcar mascavo. 2010. 97 f. Dissertação (Mestrado em
Ciências e Tecnologia de Alimentos)--Universidade de São Paulo, Piracicaba, 2010.

LOPES, C. H.; BORGES, M. T. M. R. Produção de açúcar mascavo, rapadura e melado de cana. Araras: SEBRAE, 1998.

LOPES, C. H.; BORGES, M. T. M. R. Fabricação de açúcar mascavo, rapadura e melado de cana. Araras: UFSCar, 2004a.

LOPES, C. H.; BORGES, M. T. M. R. Manual de análise de açúcar: açúcar VHP, VVHP, demerara, cristal, refinado e açúcar líquido. Araras: Sucral, 2004b.

LOPES, C. H.; BORGES, M. T. M. R. Proposta de normas e especificações para açúcar mascavo, rapadura e melado de cana. Araras: Universidade Federal de São Carlos, 2004c.

LUCHINI, P. D. Teores de nutrientes minerais e metais pesados em açúcar mascavo produzido por diferentes sistemas orgânicos e convencionais. 2014. 66 f. Dissertação (Mestrado em Ciências Agrárias)--Curso de Agroecologia e Desenvolvimento Rural, Universidade Federal de São Carlos, Araras, 2014.

MANDRO, J. L. Processo de peroxidação de açúcar tipo VHP na produção de açúcar refinado: implicações químicas, tecnológicas e microbiológicas. 2016. 97 f. Dissertação (Mestrado em Microbiologia Agrícola)--Curso de Microbiologia Agrícola, Universidade de São Paulo, Piracicaba, 2016.

PARAZZI, C.; JESUS, D. A.; LOPES, J. J. C.; VALSECHI, O. A. Análises microbiológicas do açúcar mascavo. Bioscience Journal, v. 25, p. 32-40, 2009.

SOARES, R. A. B.; GARCIA, J. C.; ZANATTA, G. S. C. C.; BRITO, M. C. Produção de cana orgânica. In: Dinardo-Miranda, L. L.; Vasconcelos; A. C. M.; Landell, M. G. A. (Ed.). Cana-de-açúcar. Campinas: IAC, 2008. p. 763-790.

VERRUMA-BERNARDI, M. R.; BORGES, M. T. M. R.; LOPES, C. H.; DELLA-MODESTA, R. C.; CECCATO ANTONINI, S. R. Avaliação microbiológica, físico-química e sensorial de açúcares mascavos comercializados na cidade de São Carlos. Brazilian Journal of Food Technology, v. 10, n. 3, p. 205-211, 2007.

ZENEBON, O.; PASCUET, N. S.; TIGLEA, P. Métodos físicoquímicos para análise de alimentos. 4. ed. São Paulo: Instituto Adolfo Lutz, 2008. 